\title{
The Drosophila Activin receptor Baboon signals through dSmad2 and controls cell proliferation but not patterning during larval development
}

\author{
Ted Brummel, ${ }^{1,7}$ Shirin Abdollah, ${ }^{2}$ Theodor E. Haerry, ${ }^{1,6}$ Mary Jane Shimell, ${ }^{1,6}$ John Merriam, ${ }^{3}$ \\ Laurel Raftery, ${ }^{4}$ Jeffrey L. Wrana, ${ }^{2}$ and Michael B. O'Connor ${ }^{1,5,6,8}$ \\ ${ }^{1}$ Department of Molecular Biology and Biochemistry, University of California, Irvine, California 92697 USA; ${ }^{2}$ Program \\ in Developmental Biology, The Hospital for Sick Children, and Department of Medical Genetics and Microbiology, \\ University of Toronto, Toronto, Canada M5G 1X8; ${ }^{3}$ Department of Biology, University of California, Los Angeles, \\ California 90024 USA; ${ }^{4}$ The Cutaneous Biology Research Center, Massachusetts General Hospital, Charlestown, \\ Massachusetts 02129 USA; ${ }^{5}$ The Howard Hughes Medical Institute, ${ }^{6}$ Department of Genetics and Cell Biology, \\ University of Minnesota, St. Paul, Minnesota 55108 USA
}

The TGF- $\beta$ superfamily of growth and differentiation factors, including TGF- $\beta$, Activins and bone morphogenetic proteins (BMPs) play critical roles in regulating the development of many organisms. These factors signal through a heteromeric complex of type I and II serine/threonine kinase receptors that phosphorylate members of the Smad family of transcription factors, thereby promoting their nuclear localization. Although components of TGF- $\beta$ /Activin signaling pathways are well defined in vertebrates, no such pathway has been clearly defined in invertebrates. In this study we describe the role of Baboon (Babo), a type I Activin receptor previously called Atr-I, in Drosophila development and characterize aspects of the Babo intracellular signal-transduction pathway. Genetic analysis of babo loss-of-function mutants and ectopic activation studies indicate that Babo signaling plays a role in regulating cell proliferation. In mammalian cells, activated Babo specifically stimulates Smad2-dependent pathways to induce TGF- $\beta$ /Activin-responsive promoters but not BMP-responsive elements. Furthermore, we identify a new Drosophila Smad, termed dSmad2, that is most closely related to vertebrate Smads 2 and 3. Activated Babo associates with dSmad2 but not Mad, phosphorylates the carboxy-terminal SSXS motif and induces heteromeric complex formation with Medea, the Drosophila Smad4 homolog. Our results define a novel Drosophila Activin/TGF- $\beta$ pathway that is analogous to its vertebrate counterpart and show that this pathway functions to promote cellular growth with minimal effects on patterning.

[Key Words: Activin; Baboon; dSmad2; optic proliferation centers; imaginal disc; TGF- $\beta$ ]

Received August 11, 1998; revised version accepted November 10, 1998.

Cytokines of the transforming growth factor- $\beta$ (TGF- $\beta$ ) superfamily are potent regulators of cell growth, differentiation, and morphogenesis (for review, see Derynck and Feng 1997; Kingsley 1994). On the basis of sequence similarities, TGF- $\beta$ molecules can be subdivided into TGF- $\beta$ s, bone morphogenetic proteins (BMPs), and Activins. All members of the TGF- $\beta$ superfamily studied to date appear to share common features in their downstream signaling mechanisms (for review, see Heldin et al. 1997). At the cell surface, these ligands associate with two classes of transmembrane serine/threonine kinases known as type I and type II receptors. The type II recep-

\footnotetext{
${ }^{7}$ Present address: Division of Biology, California Institute of Technology, Pasadena, California 91125 USA.

${ }^{8}$ Corresponding author.

E-MAIL moconnor@gene.med.umn.edu; FAX (612) 626-7031.
}

tor possesses a constitutively active intracellular kinase and, in the case of Activins and TGF- $\beta$ s, is the primary determinant of ligand recruitment. On binding ligand, the type II receptor associates with an appropriate type I partner whose intracellular domain serves as a substrate for type II-dependent phosphorylation (Wrana et al. 1994a). Phosphorylation of the type I receptor results in the activation of its kinase domain and in phosphorylation of downstream components such as the Smad transcriptional activators.

The genetic identification of a Smad protein required for BMP signaling in Drosophila (Raftery et al. 1995; Sekelsky et al. 1995) led to the isolation of related molecules in numerous other organisms (for review, see Heldin et al. 1997; Attisano and Wrana 1998). Smad family members can be grouped into subfamilies according to 
functional and phylogenetic relationships. The receptorregulated class of Smads (R-Smads) are direct substrates of the type I receptor kinase and are phosphorylated on serine residues within a carboxy-terminal SSXS motif (Macías-Silva et al. 1996; Abdollah et al. 1997; Kretzschmar et al. 1997; Liu et al. 1997b). Activation of RSmads is pathway specific. Thus, Smad1, Smad5, and Smad 8 are preferentially targeted by type I BMP receptors (Hoodless et al. 1996; Kretzschmar et al. 1997), whereas TGF- $\beta$ and Activin regulate Smad2 and Smad3 (Macías-Silva et al. 1996; Liu et al. 1997b). On phosphorylation, the R-Smads can associate with the common-mediator class of Smads represented by Smad4. After nuclear translocation of the complex (Lagna et al. 1996; Liu et al. 1997a; Zhang et al. 1997), some Smads can bind directly to DNA (Kim et al. 1997). Tissue-specific DNA binding partners, such as FAST1 or FAST2 (Chen et al. 1996; Labbé et al. 1998), are likely to help recruit the complexes to specific promoters. This recruitment facilitates the low-affinity interaction of Smads with adjacent DNA elements, which in turn enhances transcriptional responses to TGF- $\beta$ (Labbé et al. 1998), perhaps by recruiting CBP/p300 to the promoter (Feng et al. 1998; Janknecht et al. 1998). A third, more distant subfamily of Smad proteins, the inhibitory Smads, function to antagonize the activity of TGF- $\beta$ superfamily proteins (Hayashi et al. 1997; Tsuneizumi et al. 1997).

In Drosophila, representative molecules from all the different classes of TGF- $\beta$-like signaling components have been described. At the ligand level, three BMP-type factors, Decapentaplegic (Dpp), Screw (Scw), and Glass bottom boat (Gbb also known as 60A), have been identified and characterized by loss-of-function mutations (Padgett et al. 1987; Arora et al. 1994; Chen et al. 1998; Khalsa et al. 1998). Dpp is a functional ortholog of vertebrate BMPs 2 and 4 (Padgett et al. 1993) and controls many aspects of Drosophila development including the specification of dorsal tissue in the early blastoderm embryo, induction of dorsal mesoderm at germ-band extension, midgut differentiation during late embryogenesis, regulation of imaginal disc cell fate and proliferation, and regulation of follicular cell fate specification during oogenesis (Gelbart 1989; Twombly et al. 1996). The Scw and Gbb-60A ligands are more closely related to the BMP-5/BMP-6/BMP-7 subfamily, and in certain tissues, both appear to act by augmenting Dpp activity (Arora et al. 1994; Chen et al. 1998; Haerry et al. 1998; Khalsa et al. 1998). All three factors appear to share a common set of receptors that include the type II receptor Punt, and the type I receptors Thickveins (Tkv) and Saxophone (Sax) (Haerry et al. 1998 and references therein). At the intracellular level, loss-of-function mutations in Mad and the Drosophila Smad4/DPC4 homolog, Medea, suggest that both these downstream factors transduce BMPtype signals (Raftery et al. 1995; Sekelsky et al. 1995; Das et al. 1998; Hudson et al. 1998; Wisotzkey et al. 1998). In addition, an inhibitory Smad known as Dad has also been identified that appears to antagonize the Dpp signal during imaginal disc growth (Tsuneizumi et al. 1997).
Although these examples provide compelling proof for the existence of invertebrate BMP-like signaling pathways, the evidence for invertebrate TGF- $\beta$ or Activinlike signaling pathways has been scant. In this paper, we present a genetic and biochemical characterization of the Activin type I receptor Babo (Atr-I). Null mutations and germ-line clonal analysis demonstrate that baboon $(b a b o)$ is not required during embryogenesis but is essential for proper pupation and adult viablity. Loss of babo function results in late larval or early pupal lethality. The major defect in these mutants is a reduction of cell proliferation within the primordia for adult structures. Clonal analysis of babo mutants as well as overexpression of constitutively activated Babo receptors in imaginal discs further suggest that Babo primarily regulates cell proliferation and has only minimal affects on patterning. Mutations in babo do not affect the expression patterns of Dpp target genes in embryos or imaginal discs, implying that the Babo pathway is distinct from Drosophila BMP signaling. Consistent with this view, we find that activated Babo can signal to vertebrate TGF- $\beta$ /Activin, but not to BMP-responsive promoters in cell culture. Activated Babo cannot bind to or interact with Drosophila Mad in tissue culture but can utilize a new Drosophila Smad homolog, dSmad2, which is most related to the vertebrate Smads 2 and 3. Drosophila dSmad2 is highly expressed in tissues that require babo function and can be phosphorylated by either overexpression of activated Babo or by overexpression of wildtype Punt and Babo together. On the basis of these results, we propose that an Activin-like signaling pathway exists in Drosophila, which is required for proper cell proliferation in many primordial adult tissues. The identification and characterization of this pathway in Drosophila may provide additional insights into conserved features of Activin-like signaling pathways in vertebrates.

\section{Results}

babo genomic structure and identification of mutants

The babo locus maps to the $44 \mathrm{~F}-45 \mathrm{~A}$ region on the right arm of chromosome two and encodes two transcripts that differ in the sequence of their extracellular domains (Wrana et al. 1994b). The boundaries of these transcripts and their exon-intron structures were determined by comparison of different cDNA clones to genomic DNA by PCR, sequencing, and Southern blot analysis. Both babo transcripts are encoded within a 9-kb genomic fragment and contain seven exons with exon $3 \mathrm{a} / \mathrm{b}$ being differentially spliced to produce the two isoforms (Fig. 1).

For initial genetic characterization of the babo locus, we obtained all available mutations, deficiencies, and P-element transposons that mapped to this region. Using RFLP analysis, we found that two $\mathrm{P}$ elements, $\mathrm{P}[1 a c$ $\left.W^{+}\right]^{k 07737}$ and $\mathrm{P}[\mathrm{cp} 70 \mathrm{ZT}]$ were inserted near the $5^{\prime}$ end of the babo transcript. The $\mathrm{P}\left[1 a c w^{+}\right]^{k 07737}$ line is homozygous lethal, whereas the $\mathrm{P}[c p 70 Z T]$ line is homozygous viable. The exact insertion point for $\mathrm{P}\left[\mathrm{lac} \mathrm{W}^{+}\right]^{\mathrm{k} 07737}$ was 


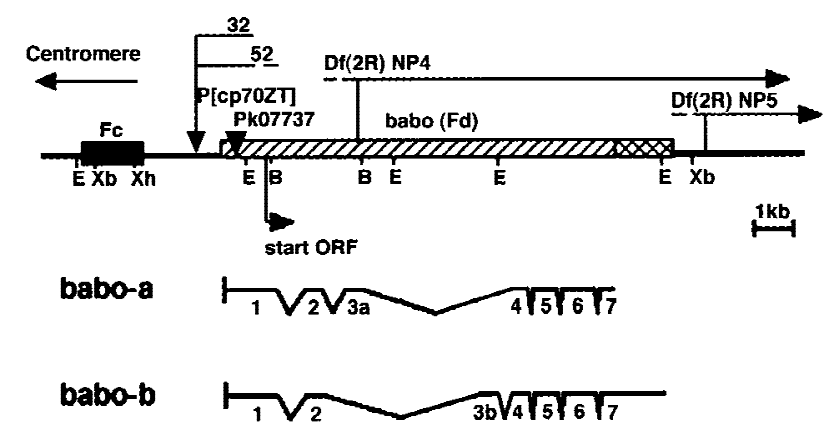

Figure 1. Schematic representation of the babo genomic region. The region is displayed with the centromere at left. The Fc and Fd loci are indicated by boxed areas. The $b a b o_{b}$ transcript contains an alternatively spliced exon 3 and an alternative polyadenylation site producing a longer transcript. $(\boldsymbol{\nabla})$ The two Pelement insertions. The uncertainties in the endpoints of deficiencies $\mathrm{Np} 4$ and $\mathrm{Np} 5$ as well as $b a b o^{32}$ and $b a b o^{52}$ are indicated by broken lines. The start site of translation is indicated by an arrow below the map. (E) EcoRI; (B) BalI; (Xb) XbaI; (Xh) Xhol.

determined, by plasmid rescue and DNA sequencing, to be in the $5^{\prime}$-untranslated region of the babo transcript at base 25. Southern blot analysis of P[cp70ZT] demonstrated that it is inserted $\sim 300$ bp upstream of the babo transcription start site.

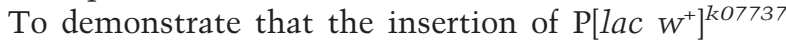
was responsible for the lethality of these flies, excisions were induced by hybrid dysgenesis. Seventy percent $(n=25)$ of the $W^{-}$excision events resulted in a reversion to viability over the original $\mathrm{P}\left[\mathrm{lac} \mathrm{W}^{+}\right]^{k 07737}$. This demonstrates that the insertion of $\mathrm{P}\left[\mathrm{lac} \mathrm{W}^{+}\right]^{\mathrm{k} 07737}$ into the $5^{\prime}$-untranslated region of babo is responsible for the lethality. Complementation testing showed that P[lac $\left.\mathrm{W}^{+}\right]^{k 07737}$ is allelic to the $\mathrm{Fd}$ complementation group of Konev et al. (1994). Other babo alleles produced by the mobilization of the $\mathrm{P}[\mathrm{cp} 70 \mathrm{ZT}]$ were identified by testing P-element lines for RFLPs in the babo region. Three of these lines, $b a b o^{52}, b a b o^{50}$, and $b a b o^{32}$, displayed polymorphisms and failed to complement $\mathrm{P}\left[\mathrm{lac} \mathrm{W}^{+}\right]^{\mathrm{kO} 7737}$ and $\mathrm{Fd}$ mutants. One line, $b a b o^{50}$, did not complement either Fd or Fc alleles and was found to be a small deletion that removed portions of both the Fd and Fc transcription units. Both the $b a b o^{52}$ and $b a b o^{32}$ mutations were the result of imprecise excision events that produced deletions eliminating the translational start site of babo (Fig. 1). Specifically, $b a b o^{32}$ deletion removed a portion of P[cp70ZT] and the first $850 \mathrm{bp}$ of the babo transcript, which includes the translational start codon and the first 53 amino acids. Southern blot analysis indicated that $b a b o^{52}$ contained a similar deletion. Therefore, $b a b o^{32}$ and $b a b o^{52}$ likely represent null alleles. In addition, we generated transgenic fly lines carrying a genomic rescue construct, $\mathrm{P}[\mathrm{Gen} b a b o]$, which contained only the babo transcription unit and $\sim 2.5 \mathrm{~kb}$ of upstream and $300 \mathrm{bp}$ of downstream DNA. The P[Gen babo] transgene fully rescued various heterozygous combinations of $\mathrm{Fd}$ alleles and homozygotes of $\mathrm{P}\left[\mathrm{lac} \mathrm{w}^{+}\right]^{\mathrm{kO} 7737}, \mathrm{babo}^{52}$, and $b a b o^{32}$.
The babo loss-of-function phenotype suggests a role for Babo in cell proliferation

The lethal phase of babo loss-of-function mutants was determined by use of embryos derived from either the null $b a b o^{32} / \operatorname{InGl}, B c$, or the hypomorphic $\mathrm{P}\left[\mathrm{lac} \mathrm{W}^{+}\right]^{k 07737} /$ In $G l, B c$ stocks. After the second instar stage, babo homozygotes could be distinguished by the absence of pigmented granules caused by the dominant Bc marker. No significant embryonic lethality was found for either line. The homozygous mutant larvae (Fig. 2B) from both lines, however, developed more slowly than balancer-containing larvae (Fig. 2A), were smaller in length, and exhibited enlarged anal pads. The penetrance for all these phenotypes approaches $100 \%$. A significant fraction of the $\mathrm{P}\left[\begin{array}{ll}\text { lac } & w^{+}\end{array}\right]^{k 07737}$ homozygotes pupate and survive to pharate adults (Table 1). On dissection, they were found to have normal thoracic cuticle and adult appendages, but portions of the abdominal cuticle were missing, suggesting a possible defect in the proliferation of the abdominal histoblasts (Fig. 2C). In contrast, very few of the $b a b o^{32}$ or $b a b o^{52}$ homozygotes progressed to the pharate stage, implying that the $\mathrm{P}\left[\mathrm{lac} \mathrm{W}^{+}\right]^{\mathrm{kO7737}}$ allele is likely to be hypomorphic. All babo alleles exhibited two additional defects: One is the failure to leave food and the second is a failure to evert the anterior spiracles upon pupation (data not shown). Because babo is maternally expressed (Wrana et al. 1994b), we also generated germline clones with both the null and hypomorphic alleles. Maternally depleted animals derived from both alleles showed a lethal phase similar to the zygotic mutants.

To investigate the cause of the lethality, we examined the internal organs from mutant third instar larvae. No significant abnormalites were noted in the morphology of the gut, fat body, or malphigian tubules. However, we did observe a severe reduction in the size of the brain hemispheres as well as a partial reduction in the size of the imaginal discs (Fig. 2). The small discs give rise to small adult structures in the dead pharates (Fig. 2D). Because the brain lobes appeared to be small, we examined the development of the visual center in babo mutants. As the eye disc matures, axons from photoreceptor cells posterior to the morphogenetic furrow fasciculate and send projections into the brain in a specific pattern (Fig. 2E). The axon bundles of photoreceptors one through six extend into the lamina, whereas those of photoreceptors seven and eight extend deeper into the medulla (Bausenwein et al. 1992). In babo mutants, photoreceptor differentiation and axon bundling proceed normally, but the axons fail to extend into the brain (Fig. 2, cf. E and F). This phenotype is consistent with a number of explanations, the simplest of which is that the medulla and lamina targets in the optic lobe fail to form.

The small size of the brains and discs might result either from a decrease in cell proliferation or an increase in cell death. To test for a reduction in cell division, larval tissue was labeled with BrdU, which is incorporated into S-phase cells. Wild-type brains displayed a characteristic mitotic replication pattern with high levels of cell division in the optic proliferation center, 


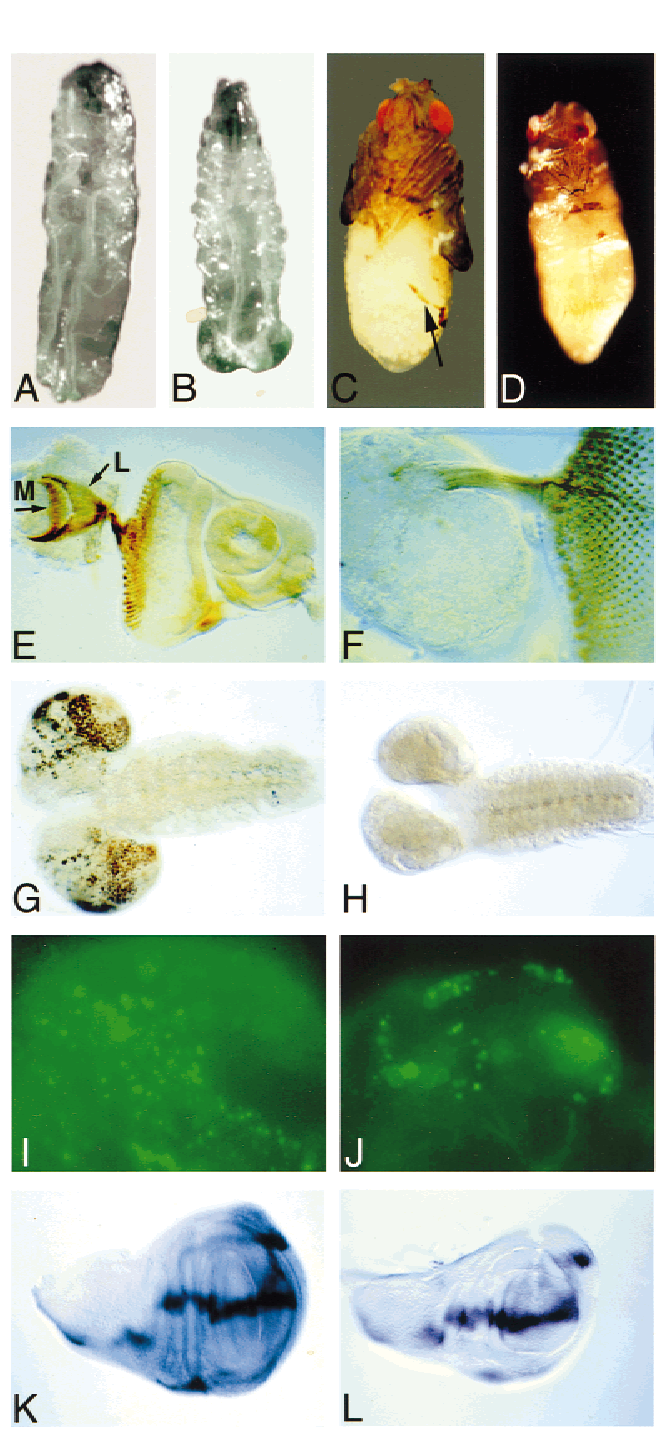

Figure 2. babo zygotic loss-of-function phenotpyes. (A) Wildtype early third instar larvae. $(B) b a b o^{32}$ null mutant early third instar larvae exhibit large anal pads and a short body. $(C)$ $b a b o^{k 07737}$ pharate adult. (Arrow) The edge of the incomplete abdominal cuticle. $(D)$ Adult structures of a $b a b o^{52} / b_{a b o} o^{32} \mathrm{mu}-$ tant derived from germ-line clones are reduced in size. (E) Wildtype eye-antennal disc and portion of a brain lobe probed with $\mathrm{mAb} 24 \mathrm{~B} 10$, which stains the R1-8 photoreceptor axons. The $\mathrm{R} 7$ and $\mathrm{R} 8$ axons reach targets in the medulla, whereas R1-6 project into the lamella (arrows). (F) $b_{a b o}{ }^{32}$ null mutant brain and eye antennal disc stained with $\mathrm{mAb} 24 \mathrm{~B} 10$. Note that the axons project to the brain but do not find their proper targets. $(G)$ BrdU labeling of a wild-type brain and ventral nerve cord. Note heavy labeling of cells in the optic proliferation centers. $(H)$ BrdU incorporation into a $b a b o^{32}$ mutant brain and ventral nerve cord. Note the small size of the brain hemispheres and the lack of actively dividing cells compared to wild type. (I) Acridine orange incorporation into a portion of a wild-type brain lobe marks dying cells. ( $J$ ) $b a b o^{32}$ mutant brain lobe stained with acridine orange shows no increase in cell death. $(K) d p p$ in situ hybridization to a wild-type late third instar wing disc. $(L)$ $d p p$ staining is unaltered in a late third instar $b a b o^{32}$ null mutant wing disc. Note the smaller size of the mutant disc.
Table 1. Survival rates

\begin{tabular}{lcll}
\hline & $\begin{array}{c}b a b o^{k 07737} \\
(\%)\end{array}$ & $\begin{array}{c}b a b o^{32} \\
(\%)\end{array}$ & $\begin{array}{c}\text { Wild } \\
\text { type }(\%)\end{array}$ \\
\hline Embryo & $90-100$ & $90-100$ & $90-100$ \\
Second & 86 & 80 & 90 \\
Third & 80 & 50 & 86 \\
Early pupa & 70 & 35 & 83 \\
Pharate & $10-30$ & $<1$ & 80 \\
Adult & 0 & 0 & 75 \\
\hline
\end{tabular}

Lethality staging of wild-type, $b a b o^{k 07737}$ and $b a b o^{32}$ mutants at $25^{\circ} \mathrm{C}$. Both $b a b o^{k 07737}$ and $b a b o^{32}$ mutants were found to grow slowly, taking an average of 2-3 days longer than wild type to pupate. We present the average from three experiments using 200 embryos each. Percent survival was determined by dividing the number of animals counted at each stage, by the number of fertilized embryos.

whereas the mutant brains showed little or no DNA replication during the time interval of BrdU incorporation (Fig. 2G,H). No striking difference in BrdU incorporation into imaginal discs was observed consistent with the observation that the discs are only $\sim 30 \%$ smaller. This slight reduction in size could be due to a more subtle change in cell proliferation or cell death. To test whether cell death might also be contributing to the reduced size of the mutant brains and discs, dying cells were stained with acridine orange. No increase in the number of dying cells was observed in either mutant brain (Fig. 2I,J) or discs (not shown). We also analyzed whether the observed reduction in cell proliferation is the result of secondary changes in the expression levels or patterns of several important growth factors. When we examined the expression of $d p p, w g$, and $h h$ in brains and discs by in situ hybridization, no significant alterations in expression levels or patterns of these genes were observed (Fig. $2 \mathrm{~K}, \mathrm{~L}$; data not shown). Taken together, these results suggest that loss of babo strongly reduces cell proliferation within the brain, whereas imaginal discs cell proliferation is affected in a more subtle way. This is accomplished without an increased cell death or noticeable alterations in the expression of several patterning genes within these tissues.

\section{The babo loss-of-function phenotype is distinct} from that exhibited by mutations in components of Drosophila BMP signaling pathways

Reduced size of imaginal discs and brain tissue is not unique to babo mutations. It is also a characteristic feature of mutations in Drosophila BMP signaling pathways (Gelbart 1989; Chen et al. 1998; Khalsa et al. 1998). Accordingly, we wished to determine whether babo could be functioning as a receptor for BMP-type ligands. In the embryo, all three characterized BMP ligands, Dpp, Scw, and $\mathrm{Gbb}$, participate in specific developmental processes. Because Scw and Dpp are both critically important for formation of the amnioserosa tissue at the blastoderm stage (Gelbart 1989; Arora et al. 1994), we used a $\mathrm{Kr}-\mathrm{lacZ}$ line to follow the fate of amnioserosa tissue in 


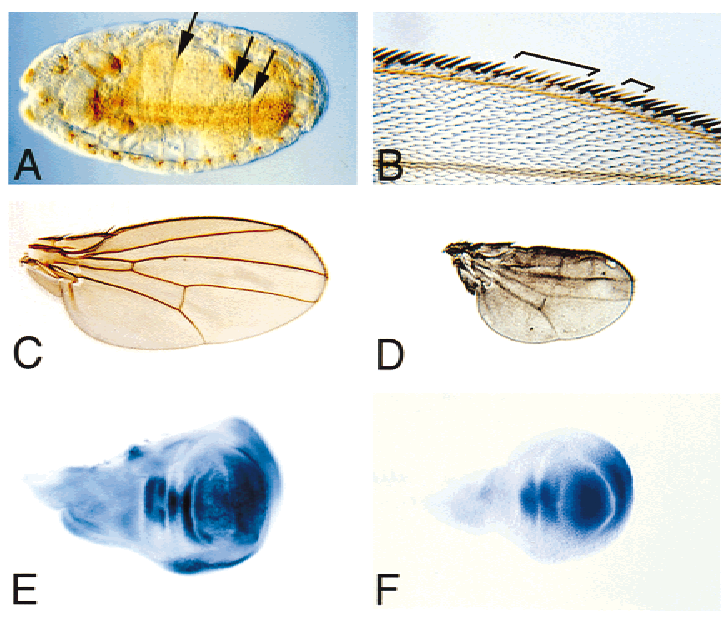

Figure 3. Clonal analysis of babo loss-of-function mutants. $(A)$ Stage $16 b_{a b o} o^{52}$ germ-line null mutant embryo showing normal midgut constrictions (arrows). (B) Wing margin clones (marked with $\left.y^{-}\right)$of $b a b o^{52}$ mutants cells show no pattern defects. $(C)$ Wild-type wing. (D) Wings of a $b a b o^{52} / b_{a b o}{ }^{32}$ germ-line clone derived from pharates are dramatically reduced in size and exhibit only minor venation defects. (E) Omb staining of a wildtype wing disc. $(F)$ Omb staining is unaltered in a $b a b o^{32}$ mutant disc.

babo mutants and found it to be unaffected (data not shown). Next, we analyzed the role of Babo in midgut development. Between stages 14 and 16, three constrictions form in the midgut producing a four-chambered vessel. Dpp is required for formation of the second midgut constriction, whereas $g b b$ mutants lack the first constriction (Chen et al. 1998; K. Wharton, pers. comm.). Mutant embryos derived from babo germ-line clones were found to exhibit a normal four-chambered midgut at stage 16 (Fig. 3A). Furthermore, visceral mesoderm expression of the Gbb target gene Antennapedia, and the Dpp target gene $U b x$, were both normal in babo mutants (data not shown). In addition to these activities, both Dpp and Gbb are required for growth and patterning of imaginal discs and larval brains (Gelbart 1989; Chen et al. 1998; Khalsa et al. 1998). Therefore, we also analyzed the expression of several target genes in babo mutant discs. In wild-type discs, the genes optormotor blind (omb) and spalt (sal) respond to Dpp in a dose-dependent fashion (Lecuit et al. 1996; Nellen et al. 1996). In addition, proper omb expression also requires input from the Gbb ligand (Haerry et al. 1998). In leg discs, Dpp represses $w g$ in the ventral portion of the disc (Theisen et al. 1996). We found no alterations in the expression patterns of $o m b, s a l$, and $w g$ in any babo mutant disc (Fig. 3E,F; data not shown). These results indicate that babo does not likely function as a receptor for Dpp, Scw, or Gbb during Drosophila development.

\section{Babo affects growth but not patterning processes}

To further determine whether babo may have an effect on imaginal disc patterning, we performed mosaic analy- sis using the FRT/FLP system (Xu and Rubin 1993). Using a Myc marker to monitor clone production in the imaginal discs, we found that clones were induced at high frequency in the discs. As shown in Table 2 however, no adult defects were found to be associated with clones in either the wing margins or legs in which we could relibably score for clones that were marked with yellow. An example of wing margin clones with no patterning defect are shown in Figure 3B. In addition to these FRT/FLP mediated adult clones, we could also occasionally obtain a pharate adult from a germ-line clone. These animals exhibited smaller appendages than wild type (Figs. 2D and 3D) but lacked major patterning defects.

We also examined the consequences of expressing a constitutively active form of Babo (Babo ${ }^{\star}$, Q302D) in imaginal discs via the UAS-Gal4 system (Brand and Perrimon 1993). Using the A9-Gal4 line (Haerry et al. 1998), we found that ubiquitous expression of the constitutively active receptor leads to tissue overgrowth in the wing, but only limited pattern abnormalities (Fig. 4A). Control experiments in which the wild-type receptor was expressed by use of the same driver showed no overgrowth. Surface area measurements indicate an $\sim 30 \%$ increase in wing size for a particular UAS-Babo* line grown at $25^{\circ} \mathrm{C}$ (Fig. 4A). To determine whether this increase in wing surface area results from an increase in cell size or number, we counted wing hairs, single apical extensions found on the surface of each wing blade cell, within a fixed area at two locations on the dorsal surface of the wing (Fig. 4B). We found an $20 \%$ increase in the density of cells at both positions compared with control flies expressing only the A9-Gal4 driver (Fig. 4B). Assuming that there is no decrease in cell death, and taking into account the $\sim 30 \%$ increase in wing size, these results suggest that for this particular transgene line, one of every two cells undergoes an extra round of division during wing formation as a result of ectopic activated Babo expression.

Table 2. Clonal analysis

\begin{tabular}{|c|c|c|c|c|c|c|}
\hline & \multicolumn{2}{|c|}{$b a b o^{k 07737}$} & \multicolumn{2}{|c|}{$b a b o^{52}$} & \multicolumn{2}{|c|}{$\begin{array}{l}\text { Wild } \\
\text { type }\end{array}$} \\
\hline $\begin{array}{l}\text { Total flies examined } \\
\text { for defects after } \\
\text { heat shock }\end{array}$ & \multicolumn{2}{|c|}{300} & \multicolumn{2}{|c|}{350} & \multicolumn{2}{|c|}{500} \\
\hline $\begin{array}{l}\text { Flies with pattern } \\
\text { defects }\end{array}$ & \multicolumn{2}{|c|}{8} & \multicolumn{2}{|c|}{10} & \multicolumn{2}{|c|}{8} \\
\hline $\begin{array}{l}\text { Flies in which } \\
\text { defects associated } \\
\text { with clones }\end{array}$ & \multicolumn{2}{|c|}{0} & \multicolumn{2}{|c|}{0} & \multicolumn{2}{|c|}{0} \\
\hline Body parts examined & wings & legs & wings & legs & wings & legs \\
\hline for clones & 90 & 85 & 80 & 90 & 30 & 35 \\
\hline \multicolumn{7}{|l|}{ Size of clones ${ }^{\mathrm{a}}$} \\
\hline large & 4 & 6 & 1 & 4 & 0 & 0 \\
\hline medium & 9 & 10 & 10 & 4 & 0 & 0 \\
\hline small & 7 & 14 & 5 & 17 & 0 & 0 \\
\hline
\end{tabular}

${ }^{a}$ (Large) more than 5 leg or wing margin bristles; (medium) 3-5 bristles; (small) 1-2 bristles. 
A
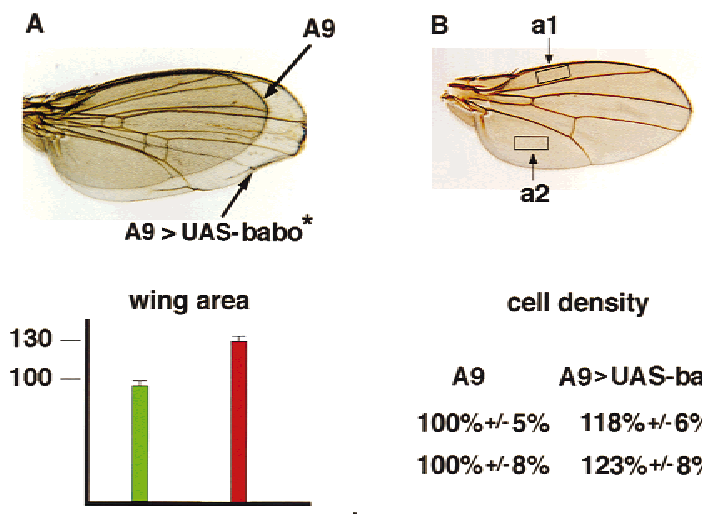

A9 A9>UAS-babo*

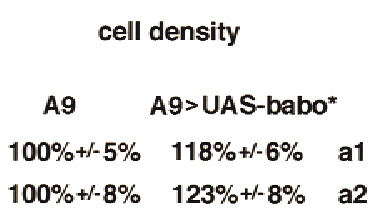

Figure 4. Overexpression of activated Babo in the wing leads to overgrowth. (A) Wings that overexpress a constitutively active Babo receptor are $\sim 30 \%$ larger than wild type. The area was determined for 12 wings of each genotype. Error bars are indicated. $(B)$ The boxes indicate the regions in which wing hairs were counted for six wings of each genotype. The average number of hairs found within these areas on A9 wings equal 100\%.

\section{Babo activates TGF- $\beta$ /Activin type response elements}

Because our genetic data indicate that in Drosophila Babo is not a component of BMP signaling, we examined the specificity of Babo activity in mammalian cell culture assays using several different pathway specific promoters. Using the TGF- $\beta /$ Activin responsive promoter p3TP fused to luciferase (p3TP-Lux; Wrana et al. 1992), we cotransfected HepG2 cells with p3TP-Lux alone or with wild-type forms of Babo or the TGF- $\beta$ type-I receptor, T $\beta$ RI (Fig. 5A). In the absence of TGF- $\beta$, only basal levels of luciferase activity were observed. As described previously (Hayashi et al. 1997), addition of TGF- $\beta$ or transfection with an activated T $\beta R I$ results in a strong induction of the p3TP-Lux promoter. A similar induction was observed when the constitutively active form of Babo was cotransfected with p3TP-Lux. In contrast, cotransfection with the constitutively active Dpp receptor Tkv, did not stimulate the 3TP reporter. Similar results were obtained with a second Activin/TGF- $\beta$ responsive element known as ARE (Hayashi et al. 1997). Cotransfection of P19 embryonic carcinoma cells with pARELux and activated Babo resulted in a fivefold induction in luciferase activity (Fig. 5B). This stimulation was similar to levels of induction produced by the activated forms of T $\beta R I$ or ActRIB. Consistent with our analysis of $3 \mathrm{TP}-$ Lux, Tkv did not modulate induction of the ARE promoter.

Finally, we examined whether activated Babo can stimulate the BMP-responsive promoter Tlx2 in P19 cells (Tang et al. 1998). Consistent with their role in $\mathrm{BMP} / \mathrm{Dpp}$ signaling, both activated Tkv and ALK6 induced the Tlx2 promoter (Fig. 5B), whereas activated Babo had no effect on this reporter. Together these data indicate that Babo specifically activates a TGF /Activin-like pathway in mammalian cells and suggest that this receptor may regulate a $\mathrm{Smad} 2 / \mathrm{Smad} 3$-like pathway in Drosophila.

\section{Cloning of dSmad2}

In Drosophila, Mad and Medea, both of which mediate Dpp signaling (Newfeld et al. 1996; Das et al. 1998; Hudson et al. 1998; Wisotzkey et al. 1998), are the only activating Smads that have been identified so far. Because Babo only appears to induce $S m a d 2 / 3$ responsive promoters in mammalian cell culture, we searched the Drosophila ESTs (Berkely Genome Project) database for new Smad-like genes. One clone with significant homology to vertebrate Smad2/3 was identified. Using this clone as a probe, we screened a Drosophila ovarian cDNA library and obtained the full-length cDNA, which was sequenced and named dSmad2. This cDNA encodes a protein of 486 amino acids and contains a carboxy-terminal SSXS motif, which is found in other receptor-regulated

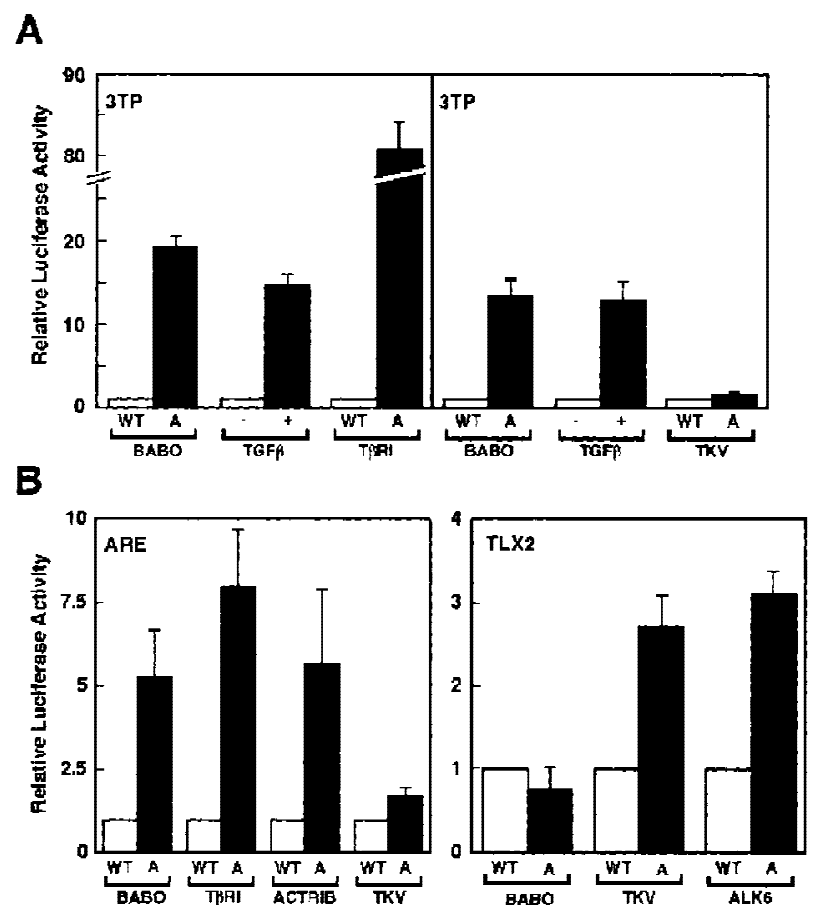

Figure 5. Activation of TGF- $\beta$ /Activin and BMP transcriptional responses in mammalian cells by Drosophila type I receptors. (A) HepG2 cells were transiently transfected with p3TP-Lux alone or with wild-type (WT, open bar) or activated (A, solid bar) forms of the indicated type I receptors. Luciferase activity was measured in cell lysates 2 days post-transfection and for each type I receptor the activity is expressed relative to luciferase activity in cells transfected with the reporter construct and the respective wild type type I receptor. To determine TGF- $\beta$-dependent induction, cells that were transfected with the reporter construct alone were treated with (solid bar) or without (open bar) 100 pM TGF- $\beta$ for $16-24 \mathrm{hr}$ prior to lysis. TGF- $\beta$-dependent induction is expressed relative to untreated cells. $(B, C)$ Signalling by Drosophila type I receptors in P19 cells. Cultures of the embryonic carcinoma cell line P19 were transfected with reporter constructs that were driven either by the ARE or the BMP-responsive Tlx2 promoter (TLX2) together with wild-type or activated forms of the indicated type I receptors. Luciferase activity in cell lysates was determined 2 days after transfection and luciferase activity is expressed as in $A$. 
SMADs (Macías-Silva et al. 1996; Abdollah et al. 1997 ; Kretzschmar et al. 1997; Liu et al. 1997; Souchelnytskyi et al. 1997). dSmad2 sequence alignment with other known Smads revealed $\sim 50 \%$ overall identity to Mad or human Smad1 and $\sim 70 \%$ identity to human Smad2 or Smad3 (Fig. 6A). Furthermore, the MH2 domain represented the region of highest homology with $>90 \%$ identity between $\mathrm{dSmad} 2$ and either Smad2 or Smad3. In the MH1 domain, dSmad2 lacks the two inserts that are found in the MH1 domain of Smad2. In the linker, dS$\operatorname{mad} 2$ contains a PY motif that is present in other Smads, but in addition has a glycine, serine, and glutamine-rich insert (amino acid residues 177-251) that is absent in either hSmad2 or hSmad3.

\section{Expression of dSmad2}

The expression pattern of dSmad2 in embryonic and lar-

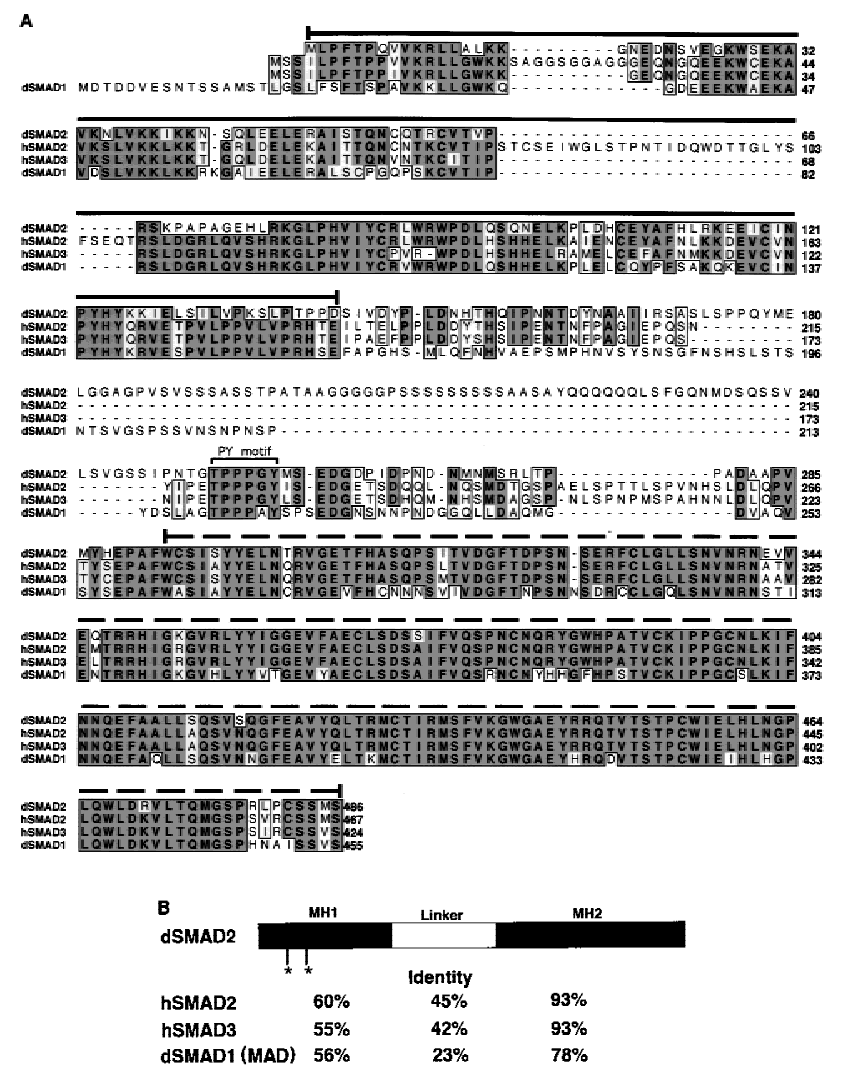

Figure 6. (A) Alignment of the predicted amino acid sequences of dSmad2, hSmad2, hSmad3, and Mad. Conserved residues (bold black type) are shaded in dark gray; letters representing similar residues are shaded light gray. (Dashes) Gaps that are introduced to maximize the alignment. The MH1 and MH2 regions of dSmad2, hSmad2, hSmad3, and Mad are indicated with solid or broken overline, respectively. The PY motif in the linker region is marked with the square bracket. (B) Schematic representation of dSmad2. Percent identity of dSmad2 relative to hSmad2, hSmad3, or Mad is listed for each of the MH1, linker, or MH2 domains. (Asterisks) The absence of the two inserts in MH1 domain of dSmad2, which are found only in hSmad2. val tissue was determined by in situ hybridization (Fig. 7). We observed high expression of dSmad2 in preblastoderm stage embryos indicating that $\mathrm{dSmad} 2$ is a maternally supplied product. The maternal message is rapidly turned over during the blastoderm stage, and the first zygotic expression of $\mathrm{dSmad} 2$ is detected during early gastrulation in the ventrally invaginating mesoderm (Fig. 7B). Enriched mesodermal expression remains throughout embryogenesis, particularly in the visceral mesoderm surrounding the midgut. In third instar larvae, we see expression in all the imaginal discs. Most notable, however, is the enriched expression in the brain lobes, specifically in the optic proliferation centers (Fig. $7 \mathrm{E})$, in which the most pronounced effects on cell proliferation are observed in babo mutants.

Babo phosphorylates dSmad2 on the last two carboxy serines and induces dSmad2-Medea interactions

The specificity of Smad interactions with receptors and nuclear targets is dictated by the $\mathrm{MH} 2$ domain. This suggests that $\mathrm{dSmad} 2$ might function in a Drosophila TGFß/Activin-like signaling pathway that involves Babo. To investigate this possibility, we tested whether Babo could mediate the phosphorylation of $\mathrm{dSmad} 2$. COS-1 cells were transfected with an epitope-tagged dSmad2 either alone or together with wild-type or constitutively active versions of Babo. Analysis of dSmad2 in the absence of signaling showed some basal phosphorylation of the protein (Fig. 8A). However, on coexpression of activated Babo, we observed a strong increase in phosphorylation of the protein (Fig. 8A). Previous work has shown that receptor-dependent phosphorylation of Smads occurs on the last two serines of the protein (Macías-Silva et al. 1996; Abdollah et al. 1997; Kretzschmar et al. 1997; Souchelnytski et al. 1997). To confirm that Babo induced phosphorylation of dSmad2 on these residues, we mutated the last two serines to alanines (dSmad2-2SA). Unlike wild-type dSmad2, this mutant was not phosphorylated by activated Babo (Fig. 8). These data suggest that $\mathrm{dSmad} 2$ is a downstream target of Babo and is phosphorylated on the last two serine residues in the carboxyl terminus.

One functional consequence of phosphorylating receptor-regulated Smads is the induction of heteromeric complex formation with the common partner Smad4 (Lagna et al. 1996; Kretzschmar et al. 1997). In Drosophila, the Smad4 homolog Medea similarly associates with Mad and is required for a subset of Dpp signaling (Wisotzkey et al. 1998). Thus, we investigated whether Babo-dependent phosphorylation of dSmad2 might induce association with Medea. In the absence of signaling, we observed that $\mathrm{dSmad} 2$ and Medea form some heteromeric complexes, however, the level of complex formation was substantially increased on cotransfection with a constitutively active form of Babo (Fig. 8B). Furthermore, use of dSmad2-2SA abolished this receptor-dependent increase in heteromeric complex formation. These data indicate that phosphorylation of $\mathrm{dSmad} 2$ on the last two 
Figure 7. dSmad2 expression pattern. Embryos, imaginal discs, and brains from a yw stock where hybridized with digoxigeninlabled antisense dSmad2 mRNA. (A) Precellularized embryo showing a strong maternal contribution of dSmad2 mRNA. $(B)$ First zygotic expression of dSmad2 appears in the invaginating mesoderm. $(C, D)$ high level dSmad2 expression in mesodermal derivatives at stage 13. (E) Brain hemisphere showing high-level dSmad2 expression in the optic proliferation center. $(F)$ Eye-antennal disc. $(G)$ First leg. $(H)$ Second leg. (I) Third leg disc. (J) Wing disc. (K) Haltere disc.

serines is necessary for receptor-dependent induction of heteromeric complexes of dSmad2 and Medea.

\section{dSmad2 interacts transiently with Babo-Punt receptor complexes}

To further characterize the activation of dSmad2, we sought to determine whether it might interact with a Babo receptor complex. Previously, we demonstrated that Punt and Babo form a heteromeric Activin receptor complex in the presence of human Activin (Wrana et al. 1994b). Because recognition of type I receptors by Smads requires activation by the type II receptor, we first confirmed that Punt can function to activate Babo by testing whether Punt/Babo complexes can induce the 3TP promoter. In HepG2 cells, transient transfection of either Punt or Babo alone had no effect on the 3TP promoter (Fig. 9). However, overexpression of Punt together with Babo led to a strong induction of the promoter. This is consistent with previous observations that type II and type I ser/thr kinase receptors have intrinsic affinity for each other and on overexpression can associate and signal in the absence of ligand (Vivien et al. 1995).

Next, we tested whether dSmad2 interacts with Punt/ Babo complexes. For this experiment, we used a kinasedeficient Babo, which functions to stabilizes Smad-receptor interactions (Macías-Silva et al. 1996). When $\mathrm{dSmad} 2$ was immunoprecipitated in the presence of wild-type receptors, no complexes could be detected (Fig. 9B). However, when the kinase-deficient form of Babo was utilized, receptor complexes coprecipitating with $\mathrm{d} S \mathrm{mad} 2$ were readily detected. In addition, when the phosphorylation site mutant of dSmad2 (2SA) was tested, we detected stable complex formation between the mutant protein and wild-type receptor complexes. We also tested for the association of Mad with Punt-Babo receptor complexes. In contrast to dSmad2, we failed to detect any receptor complexes coprecipitating with Mad even when kinase deficient Babo was used in the transfection. Thus, dSmad2 interacts transiently and specifically with PuntBabo receptor complexes. Taken together, our functional and biochemical analyses strongly suggest that $\mathrm{dSmad} 2$ is a Drosophila homolog of Smad2/Smad3 and functions as a downstream signaling component that directly interacts with Babo.

\section{Discussion \\ Components of an Activin signaling pathway in Drosophila}

Early embryonic patterning events in both vertebrates and invertebrates require signals from members of the TGF- $\beta$ superfamily. One example is the conservation in function of BMP-type molecules in organizing early axial patterning events in both amphibian and Drosophila embryos (Ferguson 1996). Whether other TGF- $\beta$ pathways also exist in lower eukaryotes and what their functions might be has been unclear. Previously, we reported that the type II receptor Punt and the type I receptor Atr-I (Babo) exhibited close sequence homology to the vertebrate Activin receptors and that they could form a complex in vitro with human Activin (Childs et al. 1993; Wrana et al. 1994b). In this paper we provide three lines of evidence for the existence of a non-BMP-type signaling pathway in Drosophila. First, we demonstrate that Babo mutants do not disrupt any of the known processes that are affected by mutations in BMP-type ligands. These include the establishment of amnioserosa cell fate, midgut morphogenesis in the embryo, and the regulation of the Dpp response genes omb, sal, and $w g$ in imaginal discs. Second, we show that in tissue culture, Babo can stimulate Activin/TGF- $\beta$, but not BMP, downstream target elements. Third, we demonstrate that Babo interacts with dSmad2, a Drosophila homolog of the vertebrate Activin/TGF- $\beta$ pathway-specific Smads, but not Mad, a BMP-specific transcriptional activator.

Although these data provide compelling evidence in favor of an Activin-like signaling pathway in Drosophila, many questions remain unresolved. One important issue is the identity of endogenous ligand(s) for Babo. Recently, Kutty et al. (1998) reported the identification of a Drosophila Activin $\beta_{\mathrm{B}}$-like subunit. In addition, a ligand, which by phylogenetic tests appears to be more closely related to the Activin/TGF- $\beta$ subfamily than to BMPs (S. Newfeld pers. comm.), can be found in the Drosophila genomic database (DS07149). Either one or both of these proteins could be the ligands for the two Babo receptor isoforms. Likewise, in vivo proof that Punt, $\mathrm{dSmad} 2$, and Medea all participate in an Activin signaling system will have to await the identification of a downstream target gene that is specifically activated by this pathway. Once 
Brummel et al.

A

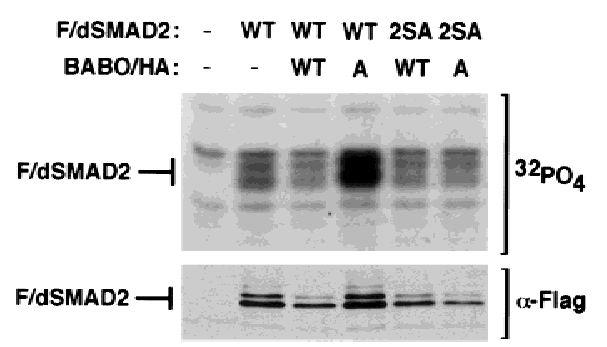

B

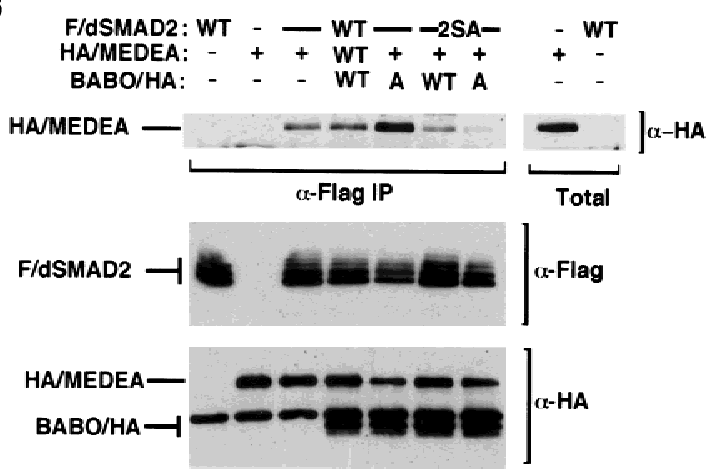

Figure 8. Activated Babo induces the phosphorylation of dS$\operatorname{mad} 2$ and formation of dSmad2-Medea heteromeric complexes. (A) COS-1 cells were transiently transfected with wild-type Flag-tagged dSmad2 (F/dSmad2) or a mutant in which the last two serines in the carboxyl terminus were mutated into alanines (2SA) together with either empty vector, wild-type (WT) or constitutively active (A) forms of Babo as indicated. Two days following transfection, cells were labeled with $\left[{ }^{32} \mathrm{P}\right]$ phosphate and Flag-tagged dSmad2 was purified by subjecting cell lysates to anti-Flag immunoprecipitation followed by SDS-PAGE and autoradiography. The migration of $\mathrm{dSmad} 2$ is marked. To determine $\mathrm{F} / \mathrm{dSmad} 2$ protein levels in each transfection, aliquots of cell lysates run in parallel were resolved by immunoblotting with antibodies against the anti-Flag epitope. $(B)$ To investigate the interaction of dSmad2 with Medea, COS-1 cells were transfected with the indicated expression constructs and cell lysates subjected to anti-Flag immunoprecipitation. The immunoprecipitates were then immunoblotted with anti-HA antibodies to detect HA/MEDEA coprecipitating with Flag/dSmad2. Aliquots of total cell lysates were probed with anti-Flag and antiHA antibodies to confirm equivalent expression of dSmad2, Medea, and Babo.

such a gene is in hand, an analysis of its expression in punt, dsmad2, and medea mutant backgrounds should answer the question of whether these genes provide endogenous components for an Activin signaling pathway.

\section{Babo influences cell growth and proliferation but not patterning}

The simplicity of the babo loss-of-function phenotype in Drosophila is striking in light of the number of speculated roles for Activin signaling in vertebrates. In particular, the fact that babo loss-of-function mutations primarily affects cell growth and proliferation in late development, but not cell fate specification or patterning processes, stands in marked contrast to the situation in vertebrates in which Activin or Activin-like signaling pathways have been implicated in a wide range of early developmental events, as well as adult functions such as reproductive potential. Similarly, in Drosophila the BMP-like factor Dpp has been implicated in the control of cell fate, cell proliferation, and patterning processes. Thus, the Babo signaling pathway appears to be unique in that it seems to act primarily in only one of these interconnected processes. It should be recognized, however, that Babo signaling may contribute to some patterning processes and/or cell fate decisions. For example, in the brain, we have yet to determine whether all of the morphological defects can be accounted for by reduced proliferation rates of certain neuroblast populations or whether there are also changes in cell fate specification.
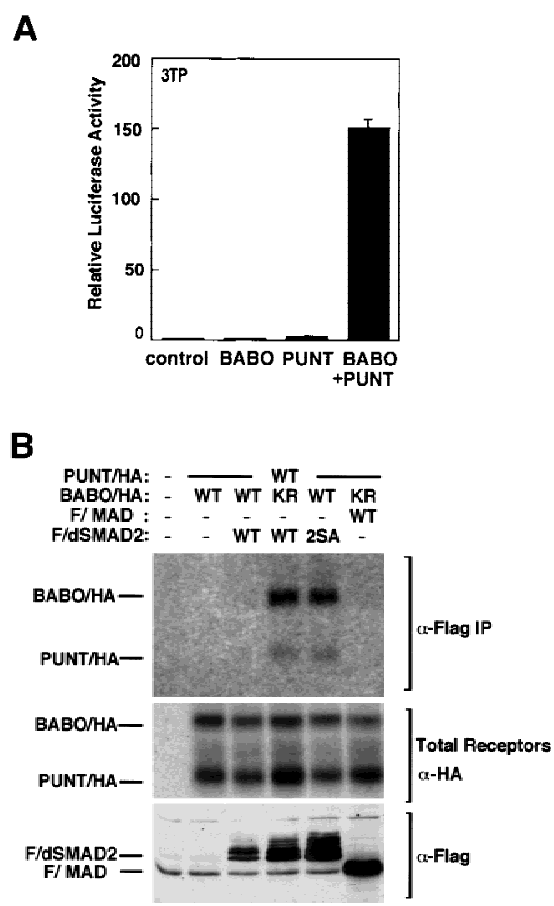

Figure 9. dSmad2 associates specifically and transiently with Babo/Punt receptor complexes. (A) Punt activates BABO in mammalian cells. HepG2 cells were transiently transfected with p3TP-Lux alone or together with the indicated combination of Babo and Punt. Luciferase activity was measured 2 days post-transfection and expressed relative to cells transfected with the reporter construct alone. $(B) \mathrm{dSmad} 2$ associates with heteromeric complexes of Babo and Punt. COS-1 cells were transfected with the indicated expression vectors and receptor complexes were affinity labeled and cross-linked with ${ }^{125} \mathrm{I}$-labeled Activin. Cell lysates were subjected to anti-Flag immunoprecipitation followed by SDS-PAGE and autoradiography to visualize receptor complexes associated with Flag/dSmad2 (anti-Flag IP). The migration of Punt/HA and Babo/HA is indicated. We confirmed equivalent receptor expression in these transfectants by analyzing aliquots of total cell lysates by SDSPAGE followed by autoradiography (total receptors), whereas expression of Flag/dSmad2 or Flag/Mad was confirmed by immunoblotting total cell lysates with anti-Flag antibodies (antiFlag blot). 
Likewise, the cause of the enlarged anal pads during larval development has not been investigated. As the anal organ is involved in regulating salt homeostasis in insects (Brugger 1974), the enlarged anal pads might simply represent swelling due to a salt imbalance or the inability to regulate water content. Larvae missing babo function also fail to exhibit a typical behavioral trait, which is to move away from moist food before pupation. Thus, the inability to assess hydration as the result of abnormal brain development may underlie both the enlarged anal pads and the failure to seek a drier climate for pupation.

At least one other signal-transducing component has been implicated in the control of imaginal disc cell growth but not patterning. Ectopic expression of the Drosophila phosphoinositide 3-kinase (PI3K), Dp110, in the wing disc results in an increase in cell proliferation but no patterning defects (Leevers et al. 1996). Likewise, reduction in the levels of PI3K via expression of dominant-negative forms reduces cell proliferation, resulting in small wings (Leevers et al. 1996) as do loss-of-function clones of babo. Whether Babo signaling could be connected to a PI3K is unclear. The PI3K pathway is generally thought to be activated via coupling to receptor tyrosine kinases. In one recent report however, the PI3K regulatory subunit $\mathrm{p} 85$ was found to bind directly to Alk5 and to stimulate PIK-3 activity under certain conditions (Krymaskay et al. 1997). This observation is intriguing because Alk5 and Alk4 are the closest vertebrate homologs of Babo receptor.

The issue of how patterning and growth are coupled in a developing tissue to regulate both size and form is not well understood. Imaginal disc development is a case in point. Despite the fact that many growth-inducing signals such as Dpp are highly localized, cell proliferation, when viewed at a global level, appears to be nearly uniform (Milán et al. 1996). At higher resolution, however, local clusters of nonclonally related cells are seen to divide in synchrony, which has led to the suggestion that some as yet undefined cell-cell communication pathway is responsible for coordinating division within small subpopulations of disc cells (Milán et al. 1996). It will be interesting to learn whether Babo might contribute to this process and how it might be tied to other growthpromoting signals like Dpp.

\section{How might Babo signaling couple to cell proliferation?}

In vertebrates, TGF- $\beta$ and Activins are known to influence the cell cycle. In the best documented cases, the effects appear to be negative and reflect alterations in the levels or activities in one or more cell cycle control proteins (for review, see Derynck and Feng 1997; Hocevar and Howe 1998). However, in certain human tumor cell lines, TGF- $\beta$ can either stimulate or inhibit cell growth via up or down regulation of a common target, p21/ Waf1/Cip1 (Miyazaki et al. 1998). Therefore, the type of response mediated by either Activin or TGF- $\beta$ likely depends on the biochemical makeup of the cell. Thus, despite the fact that most characterized examples of Ac- tivin signaling appear to be negative with respect to their effects on cell proliferation, it is not surprising that the Babo pathway appears to act in a positive manner to stimulate cell proliferation.

Recent analysis of cell growth and division in the Drosophila wing imaginal discs has led to the conclusion that the cell division rate is normally coupled to increases in cell mass such that a relatively constant ratio between the two processes is maintained (Neufeld et al. 1998). Because mutations that affect protein synthesis, such as Minutes, retard cell proliferation without changing cell size, Neufeld et al. (1998) favored a model in which tissue growth is upstream and dominant to cell cycle control. Consistent with this view, they found that if the cell cycle is artificially stimulated to give a higher division rate, then the size of the cells decreases. Conversely, if mitosis in the wing is blocked by inactivation of the Drosophila cdc2 kinase, then wings of normal size are produced but they contain smaller numbers of larger cells (Weigmann et al. 1997). We have found that overexpression of activated Babo in the wing appears to alter the process that couples growth and proliferation rates with the determination of tissue size. The simplest explanation for our results is that Babo signaling stimulates some aspect of the cell cycle resulting in an increased proliferation rate and reduced cell size similar to that described by Neufeld et al. (1998). However, the fact that we see larger wings despite the smaller cell size suggests that Babo may independently affect tissue growth parameters as well as the cell cycle. Therefore, additional studies on the mechanism of Babo signaling could help reveal how cell growth and proliferation are linked to the determination of final tissue size.

\section{Materials and methods}

babo mutant strains

The babo mutant $\mathrm{P}\left[\mathrm{lac} \mathrm{W}^{+}\right]^{\mathrm{k} 07737}$ is from (Török et al. 1993). $P$ [cp70ZT] is from Simon et al. (1985). The deficiencies Df(2R) Np4, Np5, and G75 as well as the 44F Fd and Fc alleles are described in Konev et al. (1994). The $b a b o^{32}, b_{a b o}{ }^{52}$, and $b a b o^{50}$ lines were generated by the mobilization of $P[c p 70 Z T]$. Mobilization was carried out by crossing $P[c p 70 Z T] / C y O$; Ki delta 2-3 males to $\mathrm{CyO} / \mathrm{ScO} ; \mathrm{ry}^{506}$ females in mass matings. $P[\mathrm{cp} 70 \mathrm{ZT}]^{*}$ / $\mathrm{CyO} \mathrm{Ki}^{+}$progeny were tested by crossing each fly individually to Df(2R)NP1/Gla flies. Lines in which $P[c p 70 Z T]^{\star}$ failed to complement the NP1 deficiency were saved.

\section{Mutant mapping and identification}

A genomic map of babo was generated by restriction mapping and Southern blot analysis of $\lambda$ fixII genomic phage (Stratagene) and P1 clone DS07727 from the Berkeley Drosophila genome project. Precise exon-intron boundaries were determined by PCR amplification of genomic DNA followed by cycle sequencing (Promega) and comparision to the babo cDNA sequence (Wrana et al. 1994b). The deletion endpoint of the $b a b o^{52}$ allele was determined by sequencing a 1.8 -kb Ball fragment that contained the junction between babo genomic DNA and the imprecisely excised $P[c p 70 Z T]^{*}$. 


\section{Germ-line transformation}

All germ-line transformations were carried out by standard protocols. A babo rescue construct was generated by cloning the 12-kb XhoI-XbaI genomic fragment into P[Casper Hs70]. An activated form of Babo (isoform a) was generated by changing glutamine 302 to aspartic acid (Wieser et al. 1995) via PCR mutagenesis of a full-length babo cDNA (Wrana et al. 1994b). A 3.2-kb EcoRI fragment containing the activated or wild-type form of babo was then subcloned into pUAST (Brand and Perrimon 1993).

\section{Clonal analysis}

The P $\left[1 a c W^{+}\right]^{k 07737}$ and $b a b o^{52}$ mutants were recombined onto the FRT-G13 chromosome (Chou et al. 1993). Females from these lines were crossed to males of either $y w ;$ Hs Flp; FRT-G13, $y^{+}$, or yw; Hs Flp $\pi$-Myc (Singer et al. 1997) or to yw; Hs Flp; FRT-G13 ovo ${ }^{D}$. Clones were generated by heat shocking the early first instar larvae. Adult clones were scored by the presence of $y^{-}$tissue. In discs, clones were detected by the absence of Myc staining by use of confocal microscopy. Germ-line clonal analysis was performed by crossing $\mathrm{babo}^{32} / \mathrm{Cyo}-\mathrm{wg}$ lacZ males to heatshocked females of genotype $y w$; Hs Flp; FRT-G13 $b_{a b o}{ }^{52} /$ FRT G13 ovo ${ }^{D}$. Cuticle preparations and embryo staining were performed as described in Brummel et al. (1994).

\section{Lethality staging and mutant characterization}

The lethal phase of babo mutants was determined by monitoring the development of 500 freshly laid eggs from babo/Gla,Bc stocks. Developmental timing and lethality phase were determined by counting the number of animals at each stage of both $B^{+}$and $B c^{-}$genotypes. Labeling with BrdU and acridine orange were performed as described in Tix et al. (1997) and Abrams et al. (1993), respectively. In situ hybridizations were carried out as described previously (Brummel et al. 1994). The monoclonal antibody 24B10 (gift of L. Zipursky) was used at a dilution of 1:100 and visualized with an ABC Vectastain HRP kit (Vecta Labs). The Omb antibody was a gift from G. Pflugfelder and was used at a 1:100 dilution.

\section{Cloning of dSmad2}

The clone CK 10802 was obtained from the EST database (BDGP) and used to probe an ovarian cDNA library (a gift from P. Tolias, Public Health Research Institute, New York). Of six cDNA isolates examined, all had similar-sized insert and both strands of one clone were sequenced by primer walking.

\section{Construction of expression vectors}

The construction of Babo-HA (Atr-1-HA) and Punt-HA in pCMV5 have been described previously (Child et al. 1993; Wrana et al. 1994b). pCMV5/HA-Medea is described in Wisotzkey et al. (1998). A kinase-deficient Babo was generated by mutating the lysine residue at position 330 to arginine. The introduction of each mutation was confirmed by sequencing. By use of convenient restriction sites, the amplified regions were subcloned into the appropriate plasmids containing Babo/HA. For expression in mammalian cells, full-length dSmad2 was subcloned from pBluescript into pCMV5-Flag. Serine residues 484 and 486 were changed to alanine by a PCR-based strategy to generate dSmad2 (2SA) in pCMV5. The PCR-amplified region was subcloned into the full-length Flag-dSmad2 and the mutation was confirmed by sequencing.

\section{Mammalian cell lines and transfections}

HepG2 cells were cultured in minimal essential media (MEM) containing $10 \%$ fetal calf serum and nonessential amino acids (NEAA). P19 cells were grown in MEM containing $7.5 \%$ calf serum, $2.5 \%$ fetal calf serum, and NEAA. COS-1 cells were maintained in DMEM containing high glucose and $10 \%$ fetal calf serum. The COS-1 cells were transiently transfected by the DEAE-dextran method as described previously (Attisano et al. 1996) or by lipofectamine (GIBCO-BRL), whereas HepG2 and $\mathrm{P} 19$ cells were transiently transfected with the indicated vectors by the calcium phosphate-DNA precipitation method.

\section{Transcriptional response assay}

For TGF- $\beta$ /Activin-inducible luciferase reporter assays, cells were transiently transfected with the reporter plasmid p3TP-lux (HepG2 cells) or pARE-Lux (P19 cells), pCMV- $\beta$-gal and the indicated constructs or with vector alone. For BMP-inducible luciferase reporter assays, P19 cells were transfected with pTlx2-Lux reporter construct, pCMV- $\beta$-gal and the indicated type I receptor constructs. Cells were seeded at $25 \%-50 \%$ confluency in 24-well plates and grown overnight. The medium was changed 2-3 hr prior to transfection, and cells were transfected by incubating overnight with $1.0-0.5 \mu \mathrm{g}$ of DNA per well by the calcium phosphate-DNA precipitation method as described previously (Hoodless et al. 1996). To induce the 3TPluciferase reporter, cells were incubated overnight in $100 \mathrm{pm}$ TGF- $\beta$. Luciferase activity was measured by use of the luciferase assay system (Promega) in a Berthold Lumat LB 9501 luminometer. Transfection efficiency was determined by measuring the $\beta$-galactosidase activity (Abdollah et al. 1997). All luciferase data were normalized with respect to $\beta$-galactosidase activity.

\section{Immunoprecipitations and immunoblotting}

For $\alpha$-Flag immunoprecipitations, cell lysates were subjected to immunoprecipitation with anti-Flag M2 monoclonal antibody (IBI, Eastman Kodak), followed by adsorption to protein G-sepharose (Pharmacia) as described previously (Hoodless et al. 1996) Precipitates were washed with TNTE buffer $(50 \mathrm{~mm}$ Tris- $\mathrm{HCl}$ at $\mathrm{pH} 7.4,150 \mathrm{~mm} \mathrm{NaCl}, 0.1 \%$ Triton X-100 and 1 mm EDTA), separated by SDS-PAGE, and visualized by autoradiography. For determination of Flag- or HA-tagged transfected proteins, aliquots of total cell lysates were separated by SDS-PAGE and transferred to nitrocellulose membranes. Flag-tagged and HAtagged proteins were probed with anti-Flag M2 antibody (Kodak, 1:3000 dilution) or anti-HA 12CA5 antibody (Boehringer, 1:1000 dilution), respectively, and were detected with horseradish peroxidase-conjugated anti-mouse antibody and chemiluminesence as recommended by the manufacturer (ECL kit, Amersham).

\section{Affinity labeling}

COS-1 cells transfected with DEAE-dextran were affinity labeled using $5 \mathrm{~nm}{ }^{125}$ I-labeled Activin in medium containing $0.2 \%$ fetal calf serum at $37^{\circ} \mathrm{C}$ for $30 \mathrm{~min}$ and the receptors were cross-linked to the ligand as described previously. Cells were lysed in lysis buffer containing 10\% glycerol and then subjected 
to immunoprecipitation with anti-Flag M2 monoclonal antibody as described previously (Macías-Silva et al. 1996).

\section{Acknowledgments}

We thank Joumana Jamal for help with the Southern blot analysis of babo alleles and Alexander Konev for suppling us with various deficiencies and mutants from the 45A region. We are grateful to Lil Attisano for providing a Medea expression construct, Larry Zipursky for the gift of monoclonal antibody 24B10, Jamana Jamal for help with localizing babo mutants, and Markus Friedrich for his assistance in performing the phylogenetic anlysis. This manuscript was impoved by the thoughtful comments of Micheline Laurent, Robinette Aley, and Leslie Bell. This work was supported by grants from the March of Dimes and U.S. Public Health Service (GM47462) to M.B.O. and by a grant from the American Cancer Society (DB147) to L.R. T.H. was supported by fellowships from the Ciba-Geigy Jubiläumsstiftung and the American Cancer Society-California Division. Work in J.L.W.'s laboratory was supported by grants from the National Cancer Institute of Canada with funds from the Terry Fox Run and from the Medical Research Council (MRC). J.L.W. is an MRC Scholar. M.B.O. is an Associate Investigator of the Howard Hughes Medical Institute.

The publication costs of this article were defrayed in part by payment of page charges. This article must therefore be hereby marked 'advertisement' in accordance with 18 USC section 1734 solely to indicate this fact.

\section{Note added in proof}

The accession no. for the dSmad2 sequence is AF101386.

\section{References}

Abdollah, S., S.M. Macias, T. Tsukazaki, H. Hayashi, L. Attisano, and J.L. Wrana. 1997. TbetaRI phosphorylation of Smad2 on Ser465 and Ser467 is required for Smad2-Smad4 complex formation and signaling. J. Biol. Chem. 272: 27678 27685.

Abrams, J.M., K. White, L.I. Fessler, and H. Steller. 1993. Programmed cell death during Drosophila embryogenesis. Development 117: 29-43.

Arora, K., M. Levine, and M. O'Connor. 1994. The screw gene encodes a ubiquitously expressed member of the TGF- $\beta$ family required for specification of dorsal cell fates in the Drosophila embryo. Genes \& Dev. 8: 2588-2601.

Attisano, L., J.L. Wrana, E. Montalvo, and J. Massagué. 1996. Activation of signalling by the activin receptor complex. Mol. Cell Biol. 16: 1066-1073.

Attisano, L. and J.L. Wrana. 1998. Mads and Smads in TGF $\beta$ signalling. Curr. Opin. Cell Biol. 10: 188-194.

Bausenwein, B., A.P. Dittrich, and K.F. Fischbach. 1992. The optic lobe of Drosophila melanogaster. II. Sorting of retinotopic pathways in the medulla. Cell Tissue Res. 267: 17-28.

Brand, A.H. and N. Perrimon. 1993. Targeted gene expression as a means of altering cell fates and generating dominant phenotypes. Development 118: 401-415.

Brugger, C. 1974. Research on the ultrastructure and function of the anal organ of the normal and lethal (1(3)tr) larvae of the Drosophila melanogaster. J. Insect Physiol. 20: 121-41.

Chen, X., M.J. Rubock, and M. Whitman. 1996. A transcriptional partner for MAD proteins in TGF- $\beta$ signalling. Nature 383: 691-696.
Brummel, T.J., V. Twonbly, G. Marques, J.L. Wrana, S.J. Newfeld, L. Attisano, J. Massagué, M.B. O'Connor, and W.M. Gelbart. 1994. Characterization and relationship of Dpp receptors encoded by the saxophone and thick veins gene in Drosophila. Cell 78: 251-261.

Chen, Y., M.J. Riese, M.A. Killinger, and F.M. Hoffmann. 1998. A genetic screen for modifiers of Drosophila decapentaplegic signaling identifies mutations in punt, Mothers against dpp and the BMP-7 homologue, 60A. Development 125: 17591768.

Childs, S.R., J.L. Wrana, K. Arora, L. Attisano, M.B. O'Connor, and J. Massagué 1993. Identification of a Drosophila activin receptor. Proc. Natl. Acad. Sci. 90: 9475-9479.

Chou, T.B., E. Noll, and N. Perrimon. 1993. Autosomal P[ovoD1] dominant female-sterile insertions in Drosophila and their use in generating germ-line chimeras. Development 119: $1359-1369$

Das, P., L. Maduzia, H. Wang, A. Finelli, S.H. Cho, M. Smith, and R. Padgett. 1998. The Drosophila gene Medea demonstrates the requirement for different classes of Smads in dpp signaling. Development 125: 1519-1528.

Derynck, R. and X.H. Feng. 1997. TGF-beta receptor signaling. Biochim. Biophys. Acta. 1333: F105-150.

Feng, X.H., Y. Zhang, R.Y. Wu, and R. Derynck. 1998. The tumor suppressor Smad4/DPC4 and transcriptional adaptor $\mathrm{CBP} / \mathrm{p} 300$ are coactivators for smad 3 in TGF- $\beta$-induced transcriptional activation. Genes \& Dev. 12: 2153-2163.

Ferguson, E.L. 1996. Conservation of dorsal-ventral patterning in arthropods and chordates. Curr. Opin. Genet. Dev. 6: 424431.

Gelbart, W.M. 1989. The decapentaplegic gene: A TGF- $\beta$ homolog controlling pattern formation in Drosophila. Development (Suppl.) 107: 65-74.

Haerry, T., O. Khalsa, K. O'Connor, and M. O'Connor. 1998. Synergistic signaling by two BMP ligands through the Sax and TKV receptors controls wing growth and patterning in Drosophila. Development 125: 3977-3987.

Hayashi, H., S. Abdollah, Y. Qiu, J. Cai, Y.Y. Xu, B.W. Grinnell, M.A. Richardson, J.N. Topper, M.J. Gimbrone, J.L. Wrana, and D. Falb. 1997. The MAD-related protein Smad7 associates with the TGF beta receptor and functions as an antagonist of TGF- $\beta$ signaling. Cell 89: $1165-1173$.

Heldin, C.H., K. Miyazono, and D.P. ten. 1997. TGF- $\beta$ signalling from cell membrane to nucleus through SMAD proteins. Nature 390: 465-471.

Hocevar, B.A. and P.H. Howe. 1998. Mechanisms of TGF-betainduced cell cycle arrest. Miner Electrolyte Metab. 24: 131135 .

Hoodless, P.A., T. Haerry, S. Abdollah, M. Stapleton, M.B. O'Connor, L. Attisano, and J.L. Wrana. 1996. MADR1, a MAD-related protein that functions in BMP2 signaling pathways. Cell 85: 489-500.

Hudson, J., S. Podos, K. Keith, S. Simpson, and E. Ferguson. 1998. The Drosophila Medea gene is required downstream of dpp and encodes a functional homolog of human Smad4. Development 125: 1407-1420.

Janknecht, R., N.J. Wells, and T. Hunter. 1998. TGF- $\beta$-stimulated cooperation of smad proteins with the coactivators $\mathrm{CBP} / \mathrm{p} 300$. Genes \& Dev. 12: 2114-2119.

Khalsa, O., J. Yoon, S. Torres-Schumann, and K.A. Wharton 1998. TGF- $\beta$ /BMP superfamily members, Gbb-60A and Dpp, cooperate to provide pattern information and establish cell identity in the Drosophila wing. Development 125: 2723 2734.

Kim, J., K. Johnson, H.J. Chen, S. Carroll, and A. Laughon. 1997. Drosophila Mad binds to DNA and directly mediates acti- 
vation of vestigial by Decapentaplegic. Nature 388: 304 308 .

Kingsley, D.M. 1994. The TGF- $\beta$ superfamily: New members, new receptors, and new genetic tests of function in different organisms. Genes \& Dev. 8: 133-146.

Konev, A., E.R. Varentsova, and I. Khromykh. 1994. Cytogenetic analysis of the chromosome region containing the Drosophila radiosensitivity gene. II. The vitally important loci of the 44F-45C region of chromosome 2. Genetika 30: 201211.

Kretzschmar, M., F. Liu, A. Hata, J. Doody, and J. Massagué. 1997. The TGF- $\beta$ family mediator Smadl is phosphorylated directly and activated functionally by the BMP receptor kinase. Genes \& Dev. 11: 984-995.

Krymaskay, V.P., R. Hoffman, A. Eszterhas, V. Ciocca, and R.A. Panettieri. 1997. TGF- $\beta 1$ modulates EGF-stimulated phosphatidylinositol 3-kinase activity in human airway smooth muscle cells. Am. J. Physiol. 273: 12220-12227.

Kutty, G., R.K. Kutty, W. Samuel, T. Duncan, C. Jaworski, and B. Wiggert. 1998. Identification of a new member of transforming growth factor-beta superfamily Drosophila: The first invertebrate activin gene. Biochem. Biophys. Res. Comm. 246: 644-649.

Labbé, E., C. Silvestri, P.A. Hoodless, J.L. Wrana, and L. Attisano. 1998. Smad2 and Smad3 positively and negatively regulate TGF $\beta$-dependent transcription through the forkhead DNA binding protein, FAST2. Mol. Cell 2: 109-120.

Lagna, G., A. Hata, A. Hemmati-Brivanlou, and J. Massagué. 1996. Partnership between DPC4 and SMAD proteins in TGF $\beta$ signalling pathways. Nature 383: 832-836.

Lecuit, T., W.J. Brook, M. Ng, M. Calleja, H. Sun, and S.M. Cohen. 1996. Two distinct mechanisms for long-range patterning by Decapentaplegic in the Drosophila wing. Nature 381: 387-393.

Leevers, S.J., D. Weinkove, L.K. MacDougall, E. Hafen, and M.D. Waterfield. 1996. The Drosophila phophoinositide 3-kinase Dp110 promotes cell growth. EMBO J. 15: 65846594.

Liu, F., C. Pouponnot, and J. Massagué. 1997a. Dual role of the Smad4/DPC4 tumor suppressor in TGF $\beta$-inducible transcriptional complexes. Genes \& Dev. 11: 3157-3167.

Liu, X., Y. Sun, S.N. Constantinescu, E. Karam, R.A. Weinberg, and H.F. Lodish. 1997b. Transforming growth factor betainduced phosphorylation of Smad3 is required for growth inhibition and transcriptional induction in epithelial cells. Proc. Nat1. Acad. Sci. 94: 10669-10674.

Macías-Silva, M., S. Abdollah, P.A. Hoodless, R. Pirone, L. Attisano, and J. Wrana. 1996. MADR2 is a substrate of the TGF $\beta$ receptor and its phosphorylation is required for nuclear accumulation and signalling. Cell 87: 12151224.

Milán, M., S. Campuzano, and A. García-Bellido. 1996. Cell cycling and patterned cell proliferation in the wing primordium of Drosophila. Proc. Nat1. Acad. Sci. 93: 640-645.

Miyazaki, M., R. Ohashi, T. Tsuji, K. Mihara, E. Gohda, and M. Namba. 1998. Transforming growth factor-betal stimulates or inhibits cell growth via down-or up-regulation of p21/ Waf1. Biochem. Biophys. Res. Commun. 246: 873-880.

Nellen, D., R. Burke, G. Struhl, and K. Basler. 1996. Direct and long-range action of a DPP morphogen gradient. Cell 85: $357-368$.

Neufeld, T.P., A. Flor A.della Cruz, L.A. Johnston, and B.A. Edgar. 1998. Coordination of growth and cell division in the Drosophila wing. Cell 93: 1183-1193.

Newfeld, S.J., E.H. Chartoff, J.M. Graff, D.A. Melton, and W.M. Gelbart. 1996. Mothers against dpp encodes a conserved cy- toplasmic protein required in DPP/TGF-beta responsive cells. Development 122: 2099-2108.

Padgett, R.W., R.D.S. Johnston, and W.M. Gelbart. 1987. A transcript from a Drosophila pattern gene predicts a protein homologous to the transforming growth factor-(beta) family. Nature 325: 81-84.

Padgett, R.W., J.M. Wozney, and W.M. Gelbart. 1993. Human BMP sequences can confer normal dorsal-ventral patterning in the Drosophila embryo. Proc. Natl. Acad. Sci. 90: 29052909.

Raftery, L., V. Twonbly, K. Wharton, and W.M. Gelbart. 1995. Genetic screen to identify elements of the decapentaplegic signaling pathway in Drosophila. Genetics 139: 241-254.

Sekelsky, J.J., S.J. Newfeld, L.A. Raftery, E.H. Chartoff, and W.M. Gelbart. 1995. Genetic characterization and cloning of mothers against dpp, a gene required for decapentaplegic function in Drosophila melanogaster. Genetics 139: 13471358.

Simon, J.A., C.A. Sutton, R.B. Lobell, R.L. Glaser, and J.T. Lis. 1985. Determinants of heat shock-induced chromosome puffing. Cell 40: 805-817.

Singer, M.A., A. Penton, V. Twombly, F.M. Hoffmann, and W.M. Gelbart. 1997. Signaling through both type I DPP receptors is required for anterior- posterior patterning of the entire Drosophila wing. Development 124: 79-89.

Souchelnytskyi, S., K. Tamaki, U. Engstrom, C. Wernstedt, D.P. ten, and C.H. Heldin. 1997. Phosphorylation of Ser465 and Ser467 in the C terminus of Smad2 mediates interaction with Smad4 and is required for transforming growth factorbeta signaling. J. Biol. Chem. 272: 28107-28115.

Tang, S.J., P.A. Hoodless, Z. Lu, M.L. Breitman, R.R. McInnes, J.L. Wrana, and M. Buchwald. 1998. The Tlx-2 homeobox gene is a downstream target of BMP signalling and is required for mouse mesoderm development. Development 125: $1877-1887$.

Theisen, H., T.E. Haerry, M.B. O'Connor, and J.L. Marsh. 1996. Developmental territories created by mutual antagonism between Wingless and Decapentaplegic. Development 122: 3939-3948.

Tix, S., E. Eule, K.F. Fischbach, and S. Benzer. 1997. Glia in the chiasms and medulla of the Drosophila melanogaster optic lobes. Cell Tissue Res. 289: 397-409.

Török, T., G. Tick, M. Alvarado, and I. Kiss. 1993. P-lacW insertional mutagenesis on the second chromosome of Drosophila melanogaster: Isolation of lethals with different overgrowth phenotypes. Genetics 135: 71-80.

Tsuneizumi, K., T. Nakayama, Y. Kamoshida, T.B. Kornberg, J.L. Christian, and T. Tabata. 1997. Daughters against dpp modulates dpp organizing activity in Drosophila wing development. Nature 389: 627-631.

Twombly, V., R.K. Blackman, H. Jin, J.M. Graff, R.W. Padgett, and W.M. Gelbart. 1996. The TGF-beta signaling pathway is essential for Drosophila oogenesis. Development 122: 15551565.

Vivien, D., L. Attisano, J.L. Wrana, and J. Massagué. 1995. Signaling activity of homologous and heterologous transforming growth factor-beta receptor kinase complexes. I. Biol. Chem. 270: 7134-7141.

Weigmann, K., S.M. Cohen, and C.F. Lehner. 1997. Cell cycle progression, growth and patterning in imaginal discs despite inhibition of cell division after inactivation of Drosophila Cdc2 kinase. Development 124: 3555-3563.

Wieser, R., J.L. Wrana, and J. Massagué. 1995. GS domain mutations that constitutively activate $\mathrm{T}$ beta R-I, the downstream signaling component in the TGF-beta receptor complex. EMBO J. 14: 2199-2208. 
Wisotzkey, R., A. Mehra, D. Sutherland, L. Dobens, X. Liu, C. Dohrmann, L. Attisano, and L. Raftery. 1998. Medea is a Drosophila Smad4 homolog that is differentially required to potentiate DPP responses. Development 125: 1433-1445.

Wrana, J.L., L. Attisano, J. Carcamo, A. Zentella, J. Doody, M. Laiho, X.F. Wang, and J. Massagué. 1992. TGF beta signals through a heteromeric protein kinase receptor complex. Cell 71: 1003-1014.

Wrana, J.L., L. Attisano, R. Wieser, F. Ventura, and J. Massagué. 1994a. Mechanism of activation of the TGF-beta receptor. Nature 370: 341-347.

Wrana, J.L., H. Tran, L. Attisano, K. Arora, S.R. Childs, J. Massagué, and M.B. O'Connor. 1994b. Two distinct transmembrane serine/threonine kinases from Drosophila melanogaster form an activin receptor complex. Mol. Cell. Biol. 14: 944-950.

Xu, T. and G.M. Rubin. 1993. Analysis of genetic mosaics in developing and adult Drosophila tissues. Development 117: 1223-1237.

Zhang, Y., T. Musci, and R. Derynck. 1997. The tumor suppressor Smad4/DPC 4 as a central mediator of Smad function. Curr. Biol. 7: 270-276. 


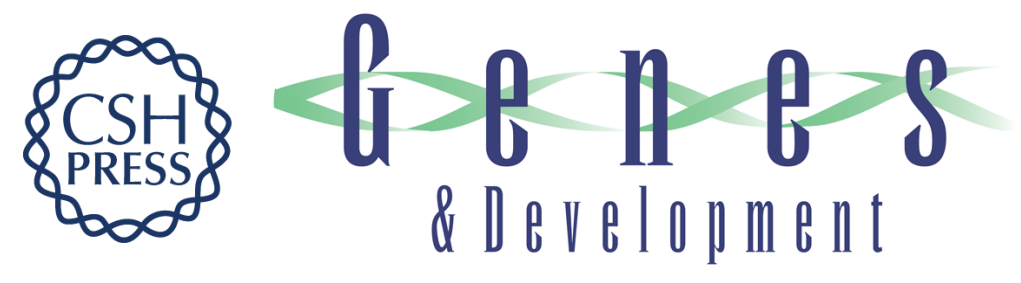

\section{The Drosophila Activin receptor Baboon signals through dSmad2 and controls cell proliferation but not patterning during larval development}

Ted Brummel, Shirin Abdollah, Theodor E. Haerry, et al.

Genes Dev. 1999, 13:

Access the most recent version at doi:10.1101/gad.13.1.98

$\begin{array}{ll}\text { References } & \begin{array}{l}\text { This article cites } 65 \text { articles, } 34 \text { of which can be accessed free at: } \\ \text { http://genesdev.cshlp.org/content/13/1/98.full.html\#ref-list-1 }\end{array}\end{array}$

License

Email Alerting Receive free email alerts when new articles cite this article - sign up in the box at the top Service right corner of the article or click here.

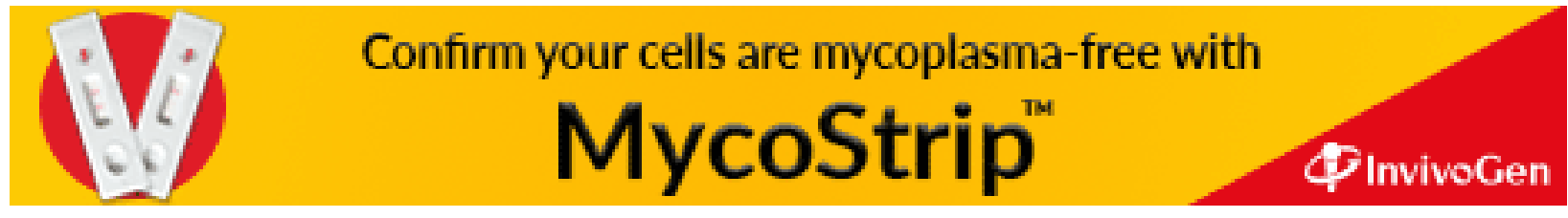

